\title{
Changing Clinical Pattern of Sheri-Amaranthji Yatra Patients Attending a Tertiary Care Centre in North-India
}

\author{
G H Yatoo, 'Mohammad Sarwar Mir, ${ }^{2}$ Shariq Rashid Masoodi ${ }^{3}$
}

1,2 Department of Hospital Administration, SKIMS Srinagar
${ }^{3}$ Department of Endocrinology SKIMS Srinagar

\section{A B S T R A C T}

INTRODUCTION: The sacred cave of Amaranth, located deep in the Himalayas, is one of the holiest pilgrimage sites of Hindu religion in general and among Shiva followers in particular. Because of high altitude, rough terrain and harsh weather, pilgrims are prone to sicknesses which sometimes may prove fatal.

OBJECTIVES: To study the profile and outcome among Shri-Amarnathji Yatra patients attending a Tertiary Care Centre in North-India, and to examine whether there is any change in the clinical pattern of yatra patients over time

METHODS: This was a prospective, observational study carried out during the yatra period of 2017. Ninety-sevenYatra patients who were on a pilgrimage toShri-Amarnathji caveand referred to SKIMS between July and August 2017 for various illnesses were studied. Allthe necessary clinical details were recorded in a pre-designed and pre-tested Proforma prepared for the study; admitted patients were followed from admission till discharge. The profile and outcome of illness of these 2017 Yatra patients were compared with the results of the study conducted in the year 2011.

RESULTS: Out of 97 Yatra patients ( referred to our Centre, 54 (55.7\%) patients were managed in the outpatient department (OPD) of the hospital; the majority of these patients $(33,61 \%)$ were male and were having minor ailments. Out of these 54 patients managed in OPD, 18 $(33 \%)$ had respiratory tract infection, while $11(20 \%)$ had Hypertension. Patients who were sick $(n=43)$ were admitted and managed in the Accident \& Emergency (A\&E) Department of the institute. Majority of the admitted patients were males (74\%); trauma, particularly road traffic accidents constituted $32.5 \%$, followed by acute myocardial infarction (16.3\%). Out of admitted 43 Yatra patients, $36(84 \%)$ patients improved, five patients (12\%) expired, one was discharged on request, and one referred to a higher centre for further management.

CONCLUSION: As compared to previous studies, moremale patients were admitted this time, most of whom were in the age-group of 21-40 years. The proportion of patients due to injury and road traffic accident has increased, forming a significant proportion of the referred cases. KEYWORDS: Amarnathji Yatra; HACE; HAPE; High-altitude illness; Hindu shrine; Holy cave; Infectious diseases; Mass-gathering medicine; Pilgrimage; Pulmonary oedema; Sickness; Trauma JMS: 2020;23(1):27-32 DOI:https://doi.org/10.33883/jms.v23i1.481

\section{INTRODUCTION}

Pilgrimage to a Holy shrine or site, a journey taken on religious grounds for spiritual purposes and innate understanding, is one of the common religious and cultural phenomena familiar to the human society throughout the world. There is a powerful politico-economic, social and cultural impact linked to pilgrimages with effect on world trade and health. it is an essential subject due to scope and spatial influence ${ }^{1}$. The holy cave of Sheri-Amarnathji is one

\begin{tabular}{l|l}
\multicolumn{3}{c}{ Access this article online } \\
\hline
\end{tabular}

of the famous pilgrimage sites of Hinduism which is great reverence for the Hindus all over the world. The place that attracts lakhs of devotees and tourists across the country (even many foreign nationals) every year, culminating into

Correspondence:

Dr. Shariq Rashid Masoodi, DM

Professor, Department of Endocrinology, SKIMS

Email: shariq.masoodi@gmail.com

How to cite this article: Sarwar M, Yatoo GH, Masoodi SR. Changing Clinical Pattern of Sheri-Amaranthji Yatra Patients Attending a Tertiary Care Centre in North-India. JMS 2020;23(1):27-32

Received: 2019-09-30 Accepted: 2020-03-16 
sacred and religious fervour ${ }^{2}$. The 130-feet high holy cave of Baba Amarnathji, situated at the height of 13000 feet $(3882 \mathrm{~m})$ and about 141kilometres from Srinagar (Jammu and Kashmir)is believed to be the abode of Lord Shiva. Two routes are available to the pilgrims, the longer route through Pahalgam (414 kilometres from Jammu) and a relatively shorterBaltal route which is about 363 kilometres from Jammu. The Yatra usually lasts for 45 days, mid-summer every year ${ }^{3}$.

Because of high altitude, rough terrain, harsh weather, the pilgrims are prone to many illnesses including respiratory and gastrointestinal infections, food poisoning, fall from a height, road traffic accidents and high altitude pulmonary oedema (HAPE) and sometimes these prove fatal ${ }^{4}$. Most of the Shri-Amarnathji yatra patients requiring superspeciality care are referred to SKIMS for treatment ${ }^{5}$. The present study was done to identify clinical profile, pattern and outcome and the Yatra patients attending SKIMS in 2017 and also to compare the results with the previous studies $^{\mathrm{s}, 6}$.

\section{MATERIALAND METHODS}

This prospective study was carried out at Sher-I-Kashmir Institute of Medical Sciences Srinagar (SKIMS), an 800bedded, super-speciality hospital in the Kashmir region of Northern India. All pilgrims of Shri-Amarnathji Yatra who were referred to SKIMS from July to August 2017 were studied. For Yatra patients admitted to the hospital, all the necessary clinical details were recorded in a pre-designed and pre-tested Proforma after the patient was stable. For patients managed in the outpatient department (OPD), all clinical details were recorded in a separate proforma prepared for this study. The details of the patient that were recorded included information on gender, age domicile status, diagnosis and outcome of the illness. Admitted patients were followed from admission until discharge from the hospital. The clinical pattern and outcome of illness in the Yatra patients in the year 2017 was compared with the results of previous years analysis of 2011 and 2015.

\section{DATAENTRYAND STATISTICALANALYSIS:}

Data were collected, coded and entered in MS Excel ${ }^{\circledR}$ on Windows PC.Data were analyzed using programme SPSS version 11.0 (Statistical Package for Social Science (Chicago: SPSSS Inc., Illinois, IL, USA). Standard methods of statistical analysis were used; nominal variables were presented as a proportion (per cent) whereas continuous variables were presented as mean \pm standard deviation. Pearson chi-square tests or Fisher Exact test(whichever appropriate) was used for comparison of dichotomous variables, whereas student's t-test was used for comparing the differences between continuous variables. An appropriate non-parametric test was used if the data were not normally distributed. A p-value of less than 0.05 was considered statistically significant.

\section{RESULTS}

The total number of patients referred to our Centre during the 2017 yatra period was 97. Among them, 60 (61.9\%) patients were males, and 37 (38.1\%) were females. The male-to-female ratio was 1.6:1. The age of the referred patients ranged from 14 to 85 , with a mean of $45.46 \pm 13.95$ and median of 45 years (Table 1). Age histogram of the study patients, inpatients as well as outpatients is shown in Figure 1. Majority of the patients (one fourth) were in the age group of 40 to 50 years. The age and sex distribution of referred Yatra patients is shown in Table 2.

Table 1. Age statistic of the 2017 Yatra patients, gender-wise

\begin{tabular}{|l|l|l|l|l|l|}
\hline Gender & $\mathrm{N}$ & Median & Mean & SD & Range \\
\hline Male & 60 & 44.5 & 45.03 & 13.96 & $14-69$ \\
\hline Female & 37 & 45.0 & 46.16 & 14.09 & $16-85$ \\
\hline All Patients & 97 & 45.0 & 45.46 & 13.95 & $14-85$ \\
\hline P $>0.05$
\end{tabular}

Table 2. Age and sex distribution of patients referred during Yatra 2017

\begin{tabular}{|l|l|l|l|l|l|l|}
\hline \multirow{2}{*}{$\begin{array}{l}\text { Age } \\
\text { group } \\
\text { (years) }\end{array}$} & \multicolumn{2}{|l|}{ Male $(\mathrm{n}=60)$} & \multicolumn{2}{l|}{$\begin{array}{l}\text { Female } \\
(\mathrm{n}=37)\end{array}$} & \multicolumn{2}{l|}{ Total (n=97) } \\
\cline { 2 - 7 } & $\mathrm{N}$ & percent & $\mathrm{N}$ & percent & $\mathrm{N}$ & percent \\
\hline$<20$ & 2 & $3.3 \%$ & 2 & $5.4 \%$ & 4 & $4.1 \%$ \\
\hline $20-29$ & 6 & $10.0 \%$ & 2 & $5.4 \%$ & 8 & $8.2 \%$ \\
\hline $30-39$ & 13 & $21.7 \%$ & 7 & $18.9 \%$ & 20 & $20.6 \%$ \\
\hline $40-49$ & 14 & $23.3 \%$ & 11 & $29.7 \%$ & 25 & $25.8 \%$ \\
\hline $50-59$ & 12 & $20.0 \%$ & 8 & $21.6 \%$ & 20 & $20.6 \%$ \\
\hline$\geq 60$ & 13 & $21.7 \%$ & 7 & $18.9 \%$ & 20 & $20.6 \%$ \\
\hline $\mathrm{P}>0.05$
\end{tabular}

Of the 97 patients referred to our Centre 54 (56\%) were managed in the outpatient department (OPD), and the remaining $43(44 \%)$ sick patients were admitted to the Accident \& Emergency ward. Figure 2 shows the clinical presentation of these 97 referred patients. The majority of referred patients had respiratory tract infection $(n=18)$, followed by road traffic accidents $(n=16)$, Hypertension 
$(n=11)$, fall from height $(n=9)$, acute gastroenteritis $(n=9)$, acute myocardial infarction $(n=7)$, high altitude cerebral oedema $(n=6)$, febrile illness $(n=4)$, nonspecific chest pain $(n=4)$, hit by shooting stone $(n=3)$, High Altitude Pulmonary Edema $(n=3)$, gas cylinder blast injury $(n=3)$, firearm injury $(n=2)$, and two cases of Diabetic ketoacidosis. The majority of patients were from Westernand Central-India $(60 \%)$ whereas the remaining $40 \%$ of patients were from North-India and Eastern-India (Figure3). Majority of the patients (40\%) were managed in the department of Neurosurgerybecause of associated head injury whereas the remaining patients were managed in other departments, like General Medicine(19\%), Cardiology (14\%), Plastic surgery (7\%), Neurology (7\%), General surgery (5\%), Endocrinology (5\%), and Cardiothoracic \& vascular surgery ( $5 \%)$.

\section{OUTCOME}

A majority (84\%) of the admitted patients were discharged in clinically stable and improved condition, whereas five patients (11\%) expired (Table 3). One patient was discharged on request and referred to a higher centre. Out of 5 patients expired, three patient expired due to RTA with severe head injury one patient expired due to HAPE with Septic shock, one patient expired with Inferior wall myocardial infarction. Inpatient hospital mortality was $11.6 \%(95 \%$ CI, 7.515 .7$)$.

\section{Table 3. Outcome of admitted patients referred} during Yatra 2017

\begin{tabular}{|l|l|l|}
\hline Outcome & Frequency & Percent \\
\hline Improved & 36 & $83.7 \%$ \\
\hline Referred to higher center & 1 & $2.3 \%$ \\
\hline Discharged on request & 1 & $2.3 \%$ \\
\hline Expired & 5 & $11.6 \%$ \\
\hline
\end{tabular}

\section{Changing clinical pattern}

The proportion of patients getting admitted in 2011 and 2017 was similar; 85 patients out of 185 (46\%) in 2011 and 43 patients out of 97 (44\%) in 2017 (Table 4). However, theproportion of male patients was significantly more in 2017 compared to 2011 (74\% vs 56\%, P <0.05). Further comparison of the data revealed that there is a significant increase in trauma cases received in the year 2017 as compared to 2011 (Table 4).

\section{DISCUSSION}

Every year, in the month of July August, lacs of devotees take the Sheri AmarnathjiYatra to pay obedience to the ice
Table 4. Comparison of clinical patternof Yatra patients: 2011vs 2017

\begin{tabular}{|l|l|l|l|}
\hline Statistic & Yatra year 2011 & Yatra year 2017 & P value \\
\hline Patients admitted, N (\%) & $85(45.9 \%)$ & $43(44.3 \%)$ & $>0.05$ \\
\hline Male inpatients, N (\%) & $48(56.5 \%)$ & $32(74.4 \%)$ & 0.048 \\
\hline Elderly inpatients (Age >65y) & $13(15.3 \%)$ & $2(4.7 \%)$ & $>0.05$ \\
\hline Clinical presentation & & & \\
\hline$-\quad$ Trauma & $23(27 \%)$ & $28(65 \%)$ & $<0.001$ \\
\hline o Polytrauma & $13(15 \%)$ & $14(33 \%)$ & 0.024 \\
\hline o Head Injury & $10(12 \%)$ & $14(33 \%)$ & 0.004 \\
\hline - Myocardial infarction & $14(16 \%)$ & $7(16 \%)$ & $>0.05$ \\
\hline - High altitude illness & $9(11 \%)$ & $9(21 \%)$ & $>0.05$ \\
\hline
\end{tabular}

stalagmite formed inside the cave. The cave is situated at a high altitude and in difficult mountainous terrain, and the weather conditions often remain harsh during the pilgrimage period. Two routes are available for Yatra, one is via Pahalgam situated in south Kashmir, and another is via Baltal situated in central Kashmir nearer to the Srinagar. Because of high altitude, rough terrain, harsh weather, pilgrims are prone to many illnesses including respiratory and gastrointestinal infections, food poisoning, fall from height, road traffic accidents, and high altitude pulmonary oedema (HAPE) which sometimes prove fatal ${ }^{7,8}$. During this Yatra, devotees are prone to illness and accidents, for special medical treatment facilities are provided en-route to the Amarnath cave.

Patients who need special treatment are referred to the statelevel health care centres like Shri Maharaja Hari Singh Hospital (SMHSH),Bone and Joint hospital (BJH) and the Sher-i-Kashmir Institute of Medical Sciences Srinagar (SKIMS). As SKIMS is the nearest tertiary care centre for the shorter Baltal route, the Yatra patients who need special care, are often referred to SKIMS for management ${ }^{7}$. High altitude religious excursions are very common in India and many experiences ill effects of high altitudes due to overenthusiasm, many people try to conceal their illness, and they face serious emergencies during the pilgrimage, posing serious problems to the organizers and authorities. The situation is further aggravated by difficult terrains, lack of infrastructure and acclimatization. To avoid fatalities government had made it mandatory for the pilgrims to undergo a medical checkup before allowing any such pilgrimage ${ }^{3}$.

On the recommendations of our previous study, a prehealth checkup of the Yatra patients before starting pilgrimage was suggested to the authorities. Also, upgradation of health care facilities enroute to the Yatra was 
Yatoo Gh etal; Changing Clinical Pattern of Sheri-Amaranthji Yatra Patients Attending a Tertiary Care Centre

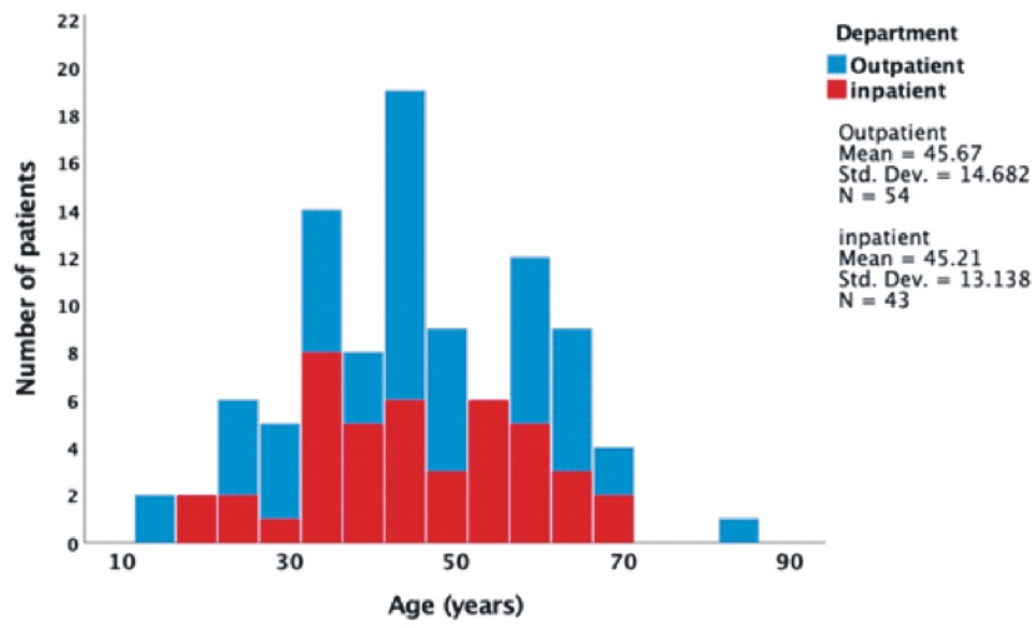

Figure 1. Age histogram of the 2017 yatra patients

\section{Clinical presentation}

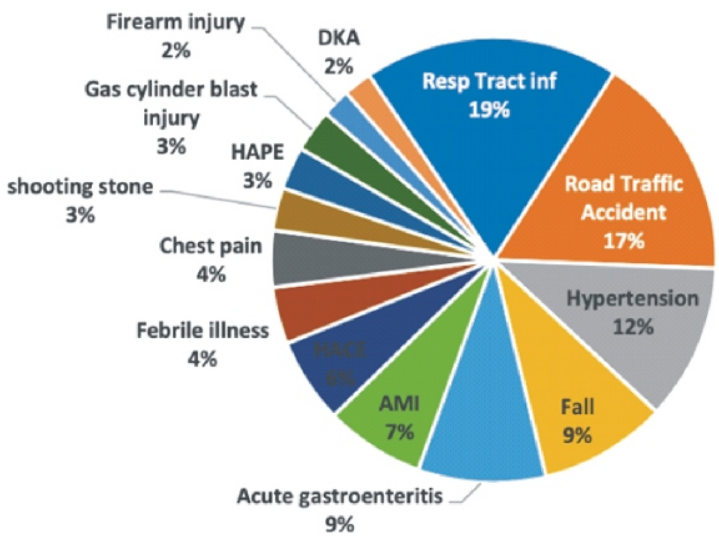

Figure 2. Clinical presentation of the Yatra patients referred to SKIMS ( $\mathrm{n}=97)$

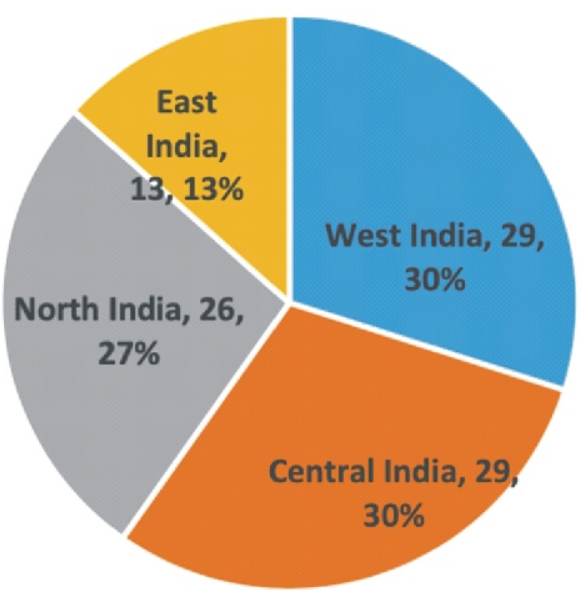

Figure 3. Geographical distribution of the referred Yatra patients 
proposed. Consequently, a significant reduction in the number of referral patients to SKIMS was observed, which was attributed to adherence to the previously given recommendations ${ }^{6}$. In the present study, we observed that trauma, road traffic accidents and other injuries were the leading cause for admissions, followed by myocardial infarction and HACE. Trauma during the pilgrimage is a real emergent problem that deserves utmost attention as most of the victims are young, healthy people in the productive age of 30-40 years.

Poorly acclimatized people from the plains are at high risk of developing various manifestations of high altitude illness, non-traumatic surgical emergencies during the holy pilgrimage to the Shri-Amarnathji cave. Many Yatra patients confessed the healthcare team to have concealed their ailments while seeking a medical certificate from the medical practitioner in their intense desire to undertake the pilgrimage. Besides, there was a general lack of awareness of the challenges posed by the tough journey. All these challenges indicate a knowledge deficit, that needs to be adequately addressed through intensive educational efforts aimed at better preparing the Yatra patients for the holy trek ${ }^{7-9}$. The pattern and outcome of illness in the Yatra patients who were referred to SKIMS in 2017 was compared with results of previous studies on the topic ${ }^{5,6}$. It was observed that in the year 2011, the total number of Yatra patients received 185, of which $100(54 \%)$ patients were having the minor ailment and were not admitted ${ }^{5}$. In present study out of 97 patients received at SKIMS, $54(56 \%)$ were having the minor ailmentand were seen on OPD basis, whereas 43 (44\%) sick patients were admitted. As compared to 2011 study majority (74\%) of the admitted were males with most being admitted because of trauma (32\%) and Acute Myocardial Infarction (16\%). While comparing these observations with those of the previous study, there was a slight increase in the number of Road Traffic Accidents and death rate (statistically insignificant), that needs to be studied in detail so as to help the authorities to better manage the health of the Yatra patients.

\section{CONCLUSION}

Whereas most of the referred Yatra patients are having minor ailments that can be managed locally, the majority of admitted patients aretrauma cases (mostly Road traffic accidents) with head injury being the most common cause of death. This calls upon the authorities for further strengthening road safety measures en-route to SheriAmarnathji Yatra so as avoid loss of precious lives. A larger prospective study is needed to get the exact profile and changing pattern of these patients. In addition, it is suggested that a) the overall Health Care and Health care Facilities to be further improved at all levels for Yatra Pilgrims, and ii) Health care infrastructure on the way to Shri-Amarnathji cave should be further improved and upgraded.

\section{Declarations:}

Conflict of interest: None

Funding: Self-funded

Written informed consent: Taken

\section{REFERENCES}

1. Bhat BA, Anees S, Geelani SNZ, Rafiqi FA, Khan SM, Nusrat. A Study on Geography of Pilgrimage Tourism and Environment: A Case Study of Kashmir Valley. International Journal of Engineering and Management Research. ISSN (Online): 2250-0758, ISSN (Print): 2394-6962. 2017;7(4):162-169.

2. SASB. A sociology lens of pilgrimage tourism in kashmir valley: a case of holy Amarnath pilgrimage. Free Online Library [Internet]. [cited 2020 Jan 1]. Available from: https://www.thefreelibrary.com/ $\mathrm{A}+$ sociology + lens + of + pilgrimage + tourism $+\mathrm{in}+\mathrm{kash}$ mir+valley\%3A+a+case+of...-a0364331943

3. SASB. Darshan of Shri Him lingam in Shri Amarnath holy cave (Gufa) [Internet]. 2018 [cited 2020 Jan 1]. Available from: http://www.shriamarnath jishrine.com/darshan_figure.html

4. Singh, J, Gorea, RK, Aggarwal, AD. Victimology of high altitude pilgrimage. J Punjab Acad Forensic Med Toxicol. 2005;5:358.

5. Yatoo G, Aubid M, Masoodi SR, Mushtaq S, Khan AS, Jan FA. Profile of Patients Attending SKIMS Srinagar during 2011 Amarnathji Yatra. JMS Ski. 2012 Dec 27;15(2):170-3.

6. Yatoo GH, Khan AS, Aubid M, Masoodi SR. Profile Of Amarnathji Yatri Patients Attending Sher-I-Kashmir Institute Of Medical Sciences Srinagar India During The Year 2015. International Journal of Medicine and 
Yatoo Gh etal; Changing Clinical Pattern of Sheri-Amaranthji Yatra Patients Attending a Tertiary Care Centre

Pharmaceutical Science (IJMPS) ISSN(P): 22500049; ISSN(E): 2321-0095. 2016;6(6): 59-66.

7. Al-Harthi AS, Al-Harbi M. Accidental injuries during muslim pilgrimage. Neurosci Riyadh Saudi Arab. $2001 \mathrm{Jul} ; 6(3): 175-7$.

8. Koul PA, Khan UH, Hussain T, Koul AN, Malik S, Shah S, et al. High altitude pulmonary edema among “Amarnath Yatris.” Lung India. 2013 Jul 1;30(3):193.
9. Yatoo, GH. Profile, Pattern and Outcome of Shri SheriAmarnathji Ji The Yatra patients attending Sher-iKashmir Institute of Medical Sciences, Srinagar, India during Holy Yatra of 2017 | Crimsonpublishers.com [Internet]. [cited 2020 Jan 1]. Available from: https://crimsonpublishers.com/oabb/fulltext/OABB.0 00525.php 